\title{
O PROTESTO NEGRO NO BRASIL CONTEMPORÂNEO (1978-2010)
}

Flavia Rios

A expressão "protesto negro" marcou a literatura acadêmica sobre movimentos sociais no Brasil porque abarcava toda sorte de ação coletiva de combate ao preconceito de cor. Desde os famosos escritos de Florestan Fernandes e Roger Bastide, esse termo se fixou na linguagem dos pesquisadores, de modo que George Andrews (1991) consolidou essa ideia ao chamar de "protesto negro" as diversas formas de manifestação de desagravo ao racismo produzidas pelos negros dos finais do Oitocentos até o centenário da Abolição. Embora esse sentido amplo guarde um significado caro aos estudos das relações raciais, o "protesto" aqui será utilizado analiticamente para investigar o "repertório de ação" (Tilly, 2005) desse movimento social. Isso porque se antes tal terminologia era útil para apreender as diferentes manifestações negras organizadas, atualmente seu uso generalista pode ofuscar a análise sobre as mobilizações contemporâneas, que já são mais complexas e extensas, vistas em contraste com as formas de períodos anteriores.

Assim nos interessa separar o protesto das práticas coletivas no interior de organizações e espaços negros. $\mathrm{O}$ 
protesto - como as marchas, passeatas, paradas, ocupações e desfiles pelas ruas -, nos ensina Tilly, assume franco objetivo de ser evento público, cuja função é chamar a atenção da sociedade e das autoridades, preferencialmente através dos holofotes ou das notícias impressas através das quais ganham mais visibilidade. Mais importante do que isso, os atos públicos são fontes privilegiadas para apreender o movimento como um todo: as alianças, as bandeiras, os oponentes, as organizações, as lideranças, os símbolos, as identidades coletivas e os discursos. Ademais, as marchas públicas permitem visualizar a trajetória do movimento social ao longo do tempo, sendo possível a verificação das regularidades dos eventos, bem como as suas possíveis inovações.

Realizado nas escadarias do Teatro Municipal de São Paulo, em 1978, o ato do Movimento Unificado Contra a Discriminação Racial (MUCDR) ${ }^{1}$ representou a forma de protesto social que o movimento negro no Brasil assumi42 ria doravante, tomando os espaços públicos abertos como palco privilegiado de manifestações. Se os anos de 1970 e 1980 viram florescer o protesto reivindicativo, no limiar do novo século os eventos públicos ganharam aspectos mais expressivos. O exemplo paradigmático desse fenômeno é a Marcha Noturna pela Democracia Racial, que ocorre na capital paulista há mais de uma década. Essa mudança pode estar relacionada à estrutura de "oportunidade política" (Tarrow, 1998; Tilly, 2005) alavancada com os processos de democratização do Brasil e ampliada pelas iniciativas dos atores coletivos diretamente interessados na pauta dos direitos sociais.

Sem estrutura para grandes mobilizações de massa em seus atos públicos iniciais, o movimento precisou construir amplas alianças através de suas entidades de base e coletivos

\footnotetext{
1 No processo de construção de sua identidade, o MNUCDR passou a se chamar tão somente MNU, Movimento Negro Unificado.
} 
organizados, para atingir um número razoável de pessoas em seus eventos. Além disso, a mobilização negra brasileira contava com outro obstáculo, o qual foi enfaticamente problematizado pela literatura acadêmica e recebeu de Hanchard ([1994] 2001) sua melhor formulação, qual seja: a hegemonia da democracia racial na cultura brasileira atuava como elemento desmobilizador das massas ${ }^{2}$. Isso levantaria um tipo de problema para os ativistas negros que não se restringia ao campo econômico e político, mas, sobretudo, ao cultural.

Porém, desde a pesquisa de campo realizada por Hanchard, nos anos de 1988 e 1989, até hoje houve muitas mudanças no país e no interior do movimento negro. Com o fito de mostrar esse quadro de modificações ao longo do tempo, serão objeto de análise o Ato Público de Fundação do MUCDR (1978), as marchas do Centenário da Abolição (1988), a Marcha do Tricentenário de Zumbi (1995) e a Marcha Noturna pela Democracia Racial (1997-2010), mediante os quais as transformações na encenação pública da luta social podem ser vistas de uma perspectiva processual.

As manifestações de rua marcaram o retorno da política negra à cena pública brasileira nos anos 1970. De lá para cá, cada vez mais, os atos do movimento negro têm tomado uma forma expressiva, litúrgica e pedagógica perante a sociedade e o Estado, enquanto outras formas de reivindicação puderam ganhar espaços institucionalizados de negociação, a exemplo das plataformas partidárias, das lutas judiciais, dos compromissos com os órgãos internacionais e com o poder público. Isso não torna as marchas, os atos e as ocupações objetos de menor relevância para o estudo dos movimentos sociais. Muito ao contrário, no protesto ence-

\footnotetext{
2 Essa foi a principal hipótese aventada por Hasenbalg ([1979] 2005) e retomada por Hanchard, que demonstrou os dilemas da desmobilização negra no Brasil devido ao mito da democracia racial, seja como ideologia difusa na sociedade, seja como política de Estado.
} 
na-se o enredo do conflito social, em sua forma simbólica e coletivamente organizada.

Na luta política, o movimento negro tenta imprimir um novo significado à ideia de Brasil e a história do país torna-se objeto de litígio. No tempo presente, luta-se pela narrativa do passado, recontada para legitimar as pautas de reivindicações sociais postas na cena pública. No protesto, busca-se, ainda, dar vivacidade à memória em retalhos, costurada pelos ativistas e carregada de emoções, sentimentos e significados para o coletivo político e, em especial, para cada sujeito envolvido na mobilização social. Nas mãos, ergue-se a bandeira do igualitarismo, tema que ganhou centralidade no ideário do grupo mobilizado nas últimas décadas do século XX.

\section{0 ato de refundação do movimento negro}

O primeiro marco dos protestos reivindicativos do movi44 mento negro contemporâneo foi o ato público promovido nas escadarias do Teatro Municipal de São Paulo, no dia 7 de junho de 1978, quando um conjunto de organizações negras de diferentes partes do país decidiu aderir ao movimento que visava combater a "discriminação" e defender "uma verdadeira democracia racial" . Comungava com essa carta de interesses o objetivo de "ampliação do movimento", seja pela adesão de outras entidades negras, seja pelo apoio dos "setores democráticos da sociedade".

A decisão de sair às ruas em protesto esteve sustentada numa avaliação ponderada de seus líderes, que perceberam a necessidade de dar mais visibilidade ao problema da discriminação racial, categoria central na nova gramática política desse movimento, quando contraposta aos ciclos de mobilização anteriores, que tinham no preconceito de cor o seu eixo argumentativo (Guimarães, 2008). Tal mudança vocabular

3 Carta aberta do Movimento Negro Unificado, citada em Gonzalez (1982, pp. 48-49). 
não significaria uma simples atualização da linguagem política contemporânea. A persuasão discursiva do movimento passou a dizer tanto sobre formas de combate às injustiças de cunho racial como acenava para transformações no padrão de valores da sociedade. Nesse sentido, uma das inovações dessa mobilização foi justamente focalizar sua pauta reivindicativa em temas que vão desde as liberdades civis dos negros, cujas vidas se viam ameaçadas pelas abordagens policiais informadas por estereótipos raciais, até a necessidade de garantir tratamento igualitário no mercado de trabalho.

A geração que assumiu a reponsabilidade de liderar o movimento social nasceu entre as décadas de 1940 e 1950, originou-se de camadas sociais populares e, em menor proporção, de estratos médios urbanos. O ingresso e a permanência nas universidades brasileiras durante a ditadura militar foi um determinante estrutural na trajetória dessa juventude. Frutos do "milagre econômico" (Rufino, 1982), jovens negros que ingressaram nos estabelecimentos de terceiro grau viram-se confrontados com mobilizações estudantis e engajamentos políticos antiditadura, correntes e formações partidárias clandestinas, todas inspiradas pelo ideário da esquerda política.

Inseridos numa rede social ampla, esses jovens passaram também a movimentar-se no sentido de problematizar a questão racial no seio desses setores autonomeados "progressistas" ou de "vanguarda". Nesses espaços, boa parte dessa juventude construiu sua formação política, dialogando com os movimentos sociais e sindicais, contestadores da ordem militar; realizando reuniões políticas em espaços de resistência ao regime, como universidades, instituições religiosas, centros estudantis, organizações partidárias e redações de jornais alternativos; questionando os alicerces da identidade nacional e conspirando, assim, contra o "mito da democracia racial”, construção ideológica que tornava cúmplices as elites do Estado e a sociedade civil submersa. 
Dessa efervescência política, formaram o Movimento Contra a Discriminação Racial, originariamente composto por negros e outras minorias étnicas (como os judeus), apresentando-se na arena pública como entidade guarda-chuva das lutas contra o racismo.

Influenciados nacionalmente pelos movimentos políticos de esquerda, pelo novo sindicalismo e pelas mobilizações estudantis (Gonzalez, 1982; Hanchard, 2001; Guimarães, 2001), os ativistas não apenas interpretaram esse ambiente político como sendo propício para a construção de um movimento nacional contra o racismo, como se utilizaram da rede social e de estratégias políticas da esquerda brasileira para construir uma ação coletiva antirracista (Hanchard, 2001). Parte significativa da intelectualidade negra, que sustentava teoricamente o movimento, articulou a linguagem marxista, notadamente no uso do conceito de classe, com a crítica social traduzida em termos raciais. Não 46 por acaso, estampado em quase todos os panfletos e manifestos políticos dessa época estava o jargão raça e classe. Nessa rasura ideológica, os intelectuais e as principais lideranças negras construiriam um discurso radical e contencioso, denunciando as práticas coletivas e representações sociais dos próprios setores progressistas do país.

A ideia de consciência negra como simbologia máxima do despertar crítico, simultaneamente individual e coletivo, do negro brasileiro, construiu-se num campo interpretativo que permitia acesso ao universo cognitivo dos intelectuais e dos ativistas de inspiração marxista, assim como era capaz de dialogar e importar "matérias simbólicas" (Ortiz, 1985) dos movimentos negros norte-americanos e africanos em suas lutas por emancipação. Todavia, ao invés de se contentarem em copiar passivamente as categorias, símbolos e estratégias das lutas internacionais, os ativistas e suas lideranças cuidaram de recriá-los à luz das peculiaridades de nossa realidade sócio-histórico-cultural, a exemplo 
de Zumbi como herói nacional (Cardoso, 1986; Saillant e Araujo, 2006). Tanto é assim que pesquisadores estrangeiros, ao analisarem as mobilizações nacionais desse período, decepcionam-se por estas não tomarem como modelo ações bem-sucedidas em seus países da luta pelos direitos civis (Bairros, 1996).

A legitimidade política do movimento apoiou-se também nos setores antirracistas da academia, que já tinham realizado estudos sobre o preconceito de cor e as desigualdades raciais (Guimarães, 1999), e nas alianças conquistadas junto aos movimentos de base identitária não classista, como o movimento feminista e, mais discretamente, a emergente mobilização dos homossexuais ${ }^{4}$. Para a formação dessa rede de ativismo, as ativistas negras foram centrais, porque transitavam nesses diferentes círculos de mobilização, agenciando as ideias políticas, traduzidas naqueles anos pela luta contra o racismo e o sexismo. Lélia Gonzalez foi a intelectual orgânica que melhor expressou essa conexão ao insistir nas alianças entre raça, classe e sexo (Ratts e Rios, 2010).

A luta antirracista fez-se, então, em diálogo, e também em concorrência com diversas tendências políticas e sociais, muitas das quais se incorporaram ao repertório do movimento negro, sem dúvida alguma devido às trajetórias, trânsitos e identidades sociais de seus ativistas, que longe de pertencerem a um movimento único, circulavam em diferentes espaços políticos, ampliando o raio de sua ação e absorvendo ideias e valores conciliáveis com seu ideário de igualdade. A despeito dessa circulação intensa, havia o desafio central para esse ativismo: a defesa da sua autonomia frente às demais organizações da sociedade civil. Delimitar as fronteiras do movimento negro era o desafio que suas lideranças e seus intelectuais teriam que enfrentar, uma vez

4 A esse respeito, ver exemplares do jornal Lampião de Esquina, produzido nos anos finais da década de 1970 . 
que esse era um dos grandes imperativos de sobrevivência de todas as mobilizações emergentes naquele período (Cardoso, 1987; Kowarick, 1987).

Estrategicamente, a escolha dos ativistas não deixava dúvida: o protesto de rua era a nova aposta para a mobilização negra que, até então, por conta da repressão militar, esteve restrita a encontros, reuniões e seminários. Eles sabiam que o ato constituía um marco para o seu repertório de ação e que as ruas passavam a ser espaços de denúncia:

Hoje estamos na rua numa campanha de denúncia! Campanha contra a discriminação racial, contra a opressão policial, contra o desemprego, o subemprego e a marginalização. Estamos nas ruas para denunciar as péssimas condições de vida da comunidade negra. Hoje é um dia histórico. Um novo dia começa a surgir para o negro! Estamos saindo das salas de reuniões, das salas de conferências e estamos indo para as ruas. Um novo passo foi dado na luta contra o racismo ${ }^{5}$.

O relato do então funcionário do Sistema Metroviário do Estado de São Paulo e estudante de economia da USP, Milton Barbosa, é bastante esclarecedor. Vindo da agremiação clandestina denominada Liga Operária e do Centro de Cultura Negra, o Cecan, um dos embriões do $\mathrm{MNU}^{6}$, Milton oferece informações valiosas acerca do estado de espírito das lideranças paulistas que encabeçavam o ato: "no dia, nos encontramos na galeria Nova Barão e saímos meio que abraçados uns com os outros" "

Amauri Mendes, já formado na UFRJ em Educação Física, e fundador da Sociedade de Intercâmbio Brasil-Africa

5 Carta aberta do MNU, citada em Gonzalez (1982, pp.48-49; grifos meus).

6 Para mais detalhes da trajetória do Cecan e sua relação com MNU, ver Joana Silva (1994).

7 Depoimento Milton Barbosa concedido a Alberti e Pereira (2007, p. 151). 
(Sinba) - uma das organizações que assinou a carta de fundação do MNU - veio do Rio de Janeiro para o evento. A sua fala reforça a insegurança e o medo que atingiam os ativistas. "Todos pareciam muito receosos, já que a possibilidade de repressão poderia ocorrer: E quem vai dar o primeiro passo? Isso era uma interrogação porque a polícia estava ali para reprimir [...] Ninguém sabe quem foi primeiro" ${ }^{8}$. Não era para menos: tratava-se do evento inaugural. E essa aparição pública foi flagrada pelos olhares atentos da mídia paulista e também não escapou ao interesse do Departamento da Ordem Política e Social (Dops), que espionou o movimento negro ao longo da década de 1970 (Kössling, 2007).

A grande liderança esperada era Abdias do Nascimento, que, ao rememorar o evento, enfatizou o quão marcante foi aquele protesto. Em sua opinião, a manifestação era a expressão da consolidação de uma nova militância, gestada durante os anos 1970:

O ato público nas escadarias do Teatro Municipal de São Paulo foi um momento inesquecível ainda em pleno regime militar. Na Bahia, no Rio de Janeiro, em Belo Horizonte e em São Paulo, participamos de reuniões de consolidação do movimento [...]. Foi ao mesmo tempo um início e um momento culminante, pois a fundação do MNU deu expressão a toda uma militância negra, que vinha se firmando através da década de 1970 (Nascimento, 2000, p. 219).

Certamente, o ato de 1978 teve o caráter explicitamente contestatório e reivindicativo, sobretudo porque naquele momento não havia ainda nenhum tipo de organização pública que pudesse servir de canal para demandas do movimento. A reivindicação, numa perspectiva estrutural, exigia o reconhecimento da existência de racismo e desi-

8 Depoimento concedido a Alberti e Pereira (2007, p. 153). 
gualdade social entre as raças, uma vez que o discurso oficial da ditadura militar baseava-se no mito da democracia racial, como afirma Guimarães:

Nos anos de ditadura militar, entre 1968 e 1978, a "democracia racial" passou a ser um dogma, uma espécie de ideologia do Estado brasileiro.

Ora, a redução do antirracismo ao antirracialismo, e sua utilização para negar os fatos de discriminação e as desigualdades raciais, crescentes no país, acabaram por formar uma ideologia racista, ou seja, uma justificativa da ordem discriminatória e das desigualdades raciais realmente existentes (1999, p. 66).

Numa perspectiva contextual, os acontecimentos imediatamente anteriores à formação do MNU foram tomados pelos ativistas como exemplos intoleráveis da discrimina50 ção no país. Tratava-se do assassinato do primo de um dos integrantes do movimento e da discriminação contra atletas negros barrados à porta do famoso Clube de Regatas do Tietê. No calor das emoções, esses eventos foram decisivos para impulsionar a atividade pública nas escadarias do Teatro Municipal.

Assim, o ato de fundação - mesmo depois que o MNU deixou de ser a sigla guarda-chuva das reivindicações negras -, tornou-se um marco referencial na história do país, porque marcou a entrada de uma nova campanha política de cunho antirracista com projeção nacional. Sueli Carneiro, hoje uma das maiores lideranças do movimento e naquela época apenas uma jovem ativista, considera que a manifestação foi o "fato político mais importante para o movimento negro contemporâneo [...], porque tudo o que ocorre depois se referencia a esse ato inaugural de refundação"9.

9 Depoimento de Sueli Carneiro concedido a Alberti e Pereira (2007, p. 148). 
De fato, o protesto inscrevia-se no repertório de ação desse movimento social que passava a figurar como mais uma das expressões públicas de uma sociedade fortemente mobilizada contra a ditadura.

\section{As marchas do centenário da Abolição}

Depois do protesto das escadarias, em 1978, o centenário da Abolição em 1988 entrou para a história do movimento negro como o segundo marco nacional da luta antirracista contemporânea. Ao contrário da fundação do MNU, a onda de manifestações que questionou a data comemorativa de 13 de Maio possuiu maior alcance, seja porque se tratava de momento simbólico para a nação, seja porque foi realizada nas proximidades da campanha pela reforma constitucional. Não era para menos: tratava-se de uma oportunidade política francamente aberta para a consolidação do movimento negro na cena política nacional.

Dez anos depois do ato no Teatro Municipal, tudo era um pouco diferente. Não só o movimento tinha se modificado, como também a conjuntura nacional estava em mudança: os ventos democráticos assobiavam mais na sociedade civil e nas estruturas estatais. De um lado, havia um processo franco de expansão e diversificação do movimento negro, revelado, sobretudo, na formação de novas organizações e na constituição dos coletivos de mulheres negras, que ampliaram o repertório discursivo do movimento, com a inclusão das questões de gênero e sexualidade. De outro lado, o movimento conquistara alguns espaços institucionais, como foi notado por Hanchard: "o protesto afro-brasileiro do fim dos anos 1970 e início dos anos 1980 levara à criação de assessorias e comissões no Rio de Janeiro e São Paulo" (2001, p.169). Assim, o protesto do 13 de Maio contava com outras condições objetivas de realização. Era, sem dúvida alguma, um movimento com mais recursos institucionais e mais experiência de ativismo. 
Os analistas não deixaram de perceber os impactos do contexto do centenário para a vida política nacional, sobretudo no que se refere à intervenção contundente do movimento negro. Lilia Schwarcz (1990) percorreu diversos eventos em São Paulo por ocasião do 13 de Maio. Muitas dessas atividades públicas tinham caráter oficial ou eram realizadas em espaços institucionais como universidades, bibliotecas e museus. Em sua descrição, percebe-se que houve uma mobilização grande por parte do Estado e instituições públicas no sentido de promover reflexões acerca do centenário. Mas o que a autora não sabia à época era que parte de tais eventos vinha das formulações de ativistas negros no interior de órgãos estatais, como o Conselho da Condição Feminina e o Conselho da Comunidade Negra ${ }^{10}$.

Muitos outros autores flagraram esses protestos através das lentes dos repórteres dos jornais brasileiros. No Rio de Janeiro, a "Marcha dos negros contra a farsa da Abolição" 52 ocorreu no dia 11 de maio de 1988, na avenida Presidente Vargas, em frente ao Panteão de Caxias. Esse evento foi reprimido pelo comando militar, que mobilizou seiscentos soldados. Para o historiador José Murilo de Carvalho, a principal reivindicação dos negros dizia respeito às alterações das condições de vida da população afro-descendente, por conta disso não se justificava a investida militar. Em suas palavras: "mesmo admitindo que houvesse da parte dos manifestantes a intenção de protestar frente ao Panteão, a reação militar, nos termos que se deu não se justificava" (2005, p. 156).

No caso carioca, tratava-se de uma situação em que o "movimento negro estava sozinho", segundo um dos coordenadores da Marcha, Ivanir dos Santos, pois "os partidos de esquerda não estavam envolvidos" ". Mas, com o impacto

\footnotetext{
${ }^{10}$ Depoimentos de Edna Roland e Sueli Carneiro consultados no Acervo do CPDOC-FGV.

${ }^{11}$ Entrevista consultada no Acervo do CPDOC-FGV.
} 
do protesto frente à opinião pública, causado pela repressão policial, muitos grupos políticos organizados apoiaram a manifestação, sobretudo porque o embate entre o Exército e o movimento social rendera espaços nos meios de comunicação.

Jacob Gorender também fez uma "cobertura" das marchas negras, usando para isso os diários locais. Segundo ele, "desde passeatas de rua a congressos acadêmicos, os eventos relacionados com a data se salientaram pela tônica da negação: não houve abolição. Em vez de festejo, repúdio" (Gorender, 1990, p. 5). Para o historiador, ao repudiar os eventos comemorativos do 13 de Maio, as mobilizações negras estavam fazendo "um julgamento de um fato histórico", qual seja, a Lei Áurea, assinada em "pena de ouro" pela princesa Isabel.

Como não foi uma marcha centralizada, a exemplo da fundação do MNU, as campanhas de rua em 1988 provocaram agitações em diferentes partes do Brasil. Gorender assinala que as discussões acerca do centenário já eram emocionantes desde o ano anterior, quando os ativistas negros incitavam a opinião pública com panfletos e debates críticos ao centenário da Abolição. Esse autor também narrou vários acontecimentos em diferentes cidades, como São Paulo, Recife e Salvador. Em todos os casos, atitudes e símbolos se repetiam seja porque queimavam uma boneca, seja porque falavam no enterro da senhora imperial: ambos simbolizando a morte da Princesa Isabel. Tendo em vista a consulta em diferentes jornais, o historiador afirma: "as comemorações ficaram apagadas e depreciadas pelos protestos dos movimentos negros na rua” (Gorender, 1990, p. 91).

Na composição do músico maranhense Tadeu de Obatalá vemos a história "oficial” do Brasil ser criticada ao sabor das passeatas de 1988. Durante o carnaval daquele ano, o bloco-afro Akomabu organizou um protesto contra as comemorações do centenário em São Luís, mas foi impedido de sair às ruas, porque as autoridades locais suspeitaram 
de que haveria alguma manifestação política ${ }^{12}$. Sem aceitar as restrições do governo, os ativistas negros saíram à avenida de surpresa "no ritmo do bloco [...] com a mão erguida"13, cantando:

13 de maio a nação nagô

não faz festa não

não faz festa não

Em protesto ao dia que diz que o libertou

E marginalizou, jogou na outra escravidão

Eu não vou festejar redentora que a história diz por aí

Redentora pra mim, foi Luiza Mahin, Pedro Ivo, Negro

Cosme e o Grande Zumbi

Recusa nação nagô falso herói que a história quer te dar

Te lembra de heróis que a chibata,

o chicote, tentaram sufocar ${ }^{14}$.

54 Nessa investida agressiva contra o 13 de Maio, o movimento não sepultava apenas uma data comemorativa alusiva à liberdade dos negros: introduzia-se na cena histórica um novo marco reivindicatório, que tinha em seu horizonte o igualitarismo. É nesse sentido que o movimento negro ergue a figura de Zumbi como símbolo da resistência negra. Não se trata apenas da troca simbólica de uma princesa branca por um guerreiro palmarino. Houve, em verdade, a assunção do tema da igualdade como bandeira política. A marcha da história fazia coro ao poema de Oswaldo de Camargo, cuja crítica ganhava eco nas lutas políticas de então: "já não há mais razão para chamar as lembranças e

12 É possível levantar a hipótese de que em capitais de alguns estados nordestinos, os blocos afros, como o Ilê Ayiê, são exemplos singulares de protesto, particularmente em sua gênese. Esta seria uma singularidade que o ativismo das outras regiões do Brasil não desenvolveu.

${ }_{13}$ Depoimento de Magno Cruz concedido a Alberti e Pereira (2007, p. 267).

${ }^{14}$ No ano de 1988, Tadeu de Obatalá compôs essa letra para Bloco Afro Akomabu, em São Luís, do Maranhão. 
mostrá-las ao povo em maio". É como se todos dissessem uma só voz: aqui jaz a Senhora Liberdade ${ }^{15}$.

\section{A marcha do tricentenário de Zumbi dos Palmares}

A década de 1980 assistiu atenta aos ativistas negros darem às costas para a data comemorativa do 13 de Maio, mas também viu o crescimento gradativo das romarias anuais em direção à Serra da Barriga, bem como o aparecimento de passeatas e eventos públicos no 20 de novembro nas ruas de diversas capitais brasileiras. As marchas ritualísticas chegaram a culminar na criação do Memorial Zumbi dos Palmares no estado de Alagoas, contudo seu efeito mais significativo foi a renovação das energias utópicas dos ativistas negros e o fortalecimento de sua identidade coletiva ancorada nas memórias da escravidão. Por sua vez, os militantes espalhados em todas as partes do país passaram a difundir a figura do guerreiro palmarino como símbolo de resistência política e cultural. Nesse caso, era mesmo o cultivo de um sentimento no âmbito do Estado-nação, isto é, significava a projeção de um símbolo político para além das fronteiras do movimento social.

Essa trajetória de mobilização sistemática teve seu ápice num grande evento em meados da década de 1990, cujo saldo foi o estabelecimento do terceiro marco do protesto negro contemporâneo: a Marcha do Tricentenário da Morte de Zumbi ${ }^{16}$. Os ativistas com experiência de realização de passeatas em seus estados ${ }^{17}$ passam a trabalhar por uma

\footnotetext{
${ }^{15}$ Os textos de Guimarães e Jesus, publicados neste dossiê, exploram justamente o caráter limitado da liberdade que o povo negro comemorou em 1888.

${ }^{16}$ Essa data já era cotada pelo movimento desde 1971, segundo Silveira (2003).

${ }_{17}$ No livro 25 anos 1980-2005: movimento negro no Brasil, o fotografo Januário Garcia registrou várias caminhadas de protesto em Alagoas, Brasília e, sobretudo, no Rio e Janeiro, ao longo dos anos 1980 e início dos 1990. Todas tinham como mote principal a homenagem a Zumbi dos Palmares, como a campanha carioca de 1983, cujo tema era "Zumbi vive". Ao longo desses anos foi construído um consenso em todo país acerca do Dia Nacional da Consciência Negra, o 20 de Novembro (Garcia, 2006).
} 
manifestação nacional, unificadora do movimento social já marcado por diversificadas e numerosas organizações. A caminhada pela Explanada dos Ministérios, em Brasília, aconteceu numa segunda-feira do dia 20 de novembro de 1995, na gestão de Fernando Henrique Cardoso.

Cerca de 30 mil pessoas caminharam em rememoração ao tricentenário da morte do herói quilombola, em cuja passeata via-se o seguinte lema: "Contra o racismo, pela cidadania e a vida". No documentário da Marcha Zumbi dos Palmares ${ }^{18}$, as passagens editadas mostram os ativistas cantando e dizendo em alto e bom tom as seguintes frases de efeito: "Reaja à violência racial!"; "Negro também quer poder!"; "Palmares! Zumbi! Assim eu resisti!"; "Queremos escola, queremos emprego!”; "Zumbi vive, Racismo, não!”. Essas cinco palavras de ordem são, provavelmente, apenas algumas dentre vários dizeres coletivos pronunciados ao longo da caminhada. Neles, mesclam-se problemas de ordem econômica, educacional e de representação política, bem como a denúncia da desigualdade e discriminação.

Enquanto as pessoas seguiam o curso da marcha pelas esplanadas, no caminhão de som, levantavam-se algumas lideranças e personalidades artísticas e parlamentares, dentre elas, Benedita da Silva, que, durante sua primeira legislatura como deputada federal, atuou na Assembleia Nacional Constituinte em favor da causa negra, indígena e de outros segmentos sub-representados, o que lhes valia a alcunha de

\footnotetext{
18 Algumas das palavras de ordem do evento foram captadas pelas filmagens feitas para a elaboração do audiovisual sobre a passeata, o qual, aliás, tem o mérito de coletar imagens e discursos de importantes líderes no calor do evento. Contudo apresenta forte viés ideológico, a se notar pelas preferências partidárias e pela quase ausência de líderes de organizações negras rivais. Mas para efeito de nossa argumentação, o filme é uma fonte relevante, em que pese o enfoque nas lideranças da CUT e do PT. O documentário foi realizado pela Ipê-vídeos produções. Dentre os apoiadores encontram se o MNU-DF; CUT; Sindicato dos Jornalistas; Ministérios dos Direitos Humanos, dentre outros. O roteiro e direção foram de Edna Cristina, com narração de Chico Sant'Anna e texto e edição realizados por Roberto Menezes.
} 
minorias políticas. Naquele dia, ela discursava em tom eloquente: "Nós queremos que esse Brasil mostre a sua cara negra" ${ }^{19}$. Numa evidente demonstração de descontentamento com a representação nacional do brasileiro, a então senadora opõe-se à versão mestiça do país e convoca o orgulho negro, especificamente da mulher negra, uma identidade autônoma que vinha ganhando fôlego nos últimos anos em interface com o movimento feminista.

Esse evento já acena para um elemento novo em relação às marchas anteriores. $\mathrm{O}$ apoio ao movimento negro parece ter crescido e se tornado mais explícito, composto por alianças diversas, como organizações de comunidades rurais, associações de trabalhadores, sindicatos e movimentos populares, só para ficar com alguns exemplos. Bandeiras partidárias se fazem notar ao lado de faixas de organizações sindicais e banners da passeata. E isso foi tão importante para o movimento que um dos membros da comissão nacional da marcha e integrante do MNU, Edson Cardoso, fez questão de registrar o empenho do então presidente da CUT:

Gostaríamos de fazer uma menção especial à participação de Vicente Paulo da Silva, Vicentinho, presidente da Central Única dos Trabalhadores (CUT), que desde a aprovação da proposta da Marcha levada pelo Movimento Negro unificado (MNU) ao encontro de sindicalistas negros cutistas, realizado em maio de 1995, em Brasília, desempenhou importante papel na garantia da aliança, muitas vezes conturbada, entre o movimento negro e o movimento sindical, sem nenhuma dúvida uma das razões essenciais do êxito alcançado pela Marcha (Marcha de Zumbi dos Palmares, 1995b).

${ }^{19}$ Discurso extraído do documentário Zumbi dos Palmares, consultado em acervo particular. 
$\mathrm{O}$ agradecimento ao sindicalista talvez não seja apenas uma referência protocolar. Note-se bem que a referência de Cardoso remete ao encontro de sindicalistas negros da CUT, o que denota um tipo de relação mais antiga. Por isso, parece não se tratar somente de uma gratidão pública referente ao empenho contextual e aos apoios eventuais da liderança e de sua estrutura, solidarizados com a "causa negra”, o que já poderia ser motivo suficiente para palavras de reconhecimento. Se não é exatamente assim, então, que tipo de alianças seriam estas? Que trocas simbólicas estavam em jogo entre o movimento negro e o sindicalismo? Quem é esse Vicentinho da Marcha de Zumbi? Seria o mesmo das greves gerais do ABC paulista?

Avento a hipótese de que Vicentinho, mais do que apoiar esse protesto como um sindicalista, estava assumindo nacionalmente o status político de líder negro. Isso pode ser notado pelas roupas que vestia e ainda pelo modo como o sindicalista se portava na marcha ${ }^{20}$. É possível supor que Edson Cardoso, ao destacar a figura de Vicentinho, já não quisesse somente agradecer a uma liderança nacional do movimento sindicalista, mas acenar para uma liderança oriunda do sindicalismo que emergia timidamente no movimento negro, assumindo assim as suas filiações identitárias, de negro e de sindicalista ${ }^{21}$.

Nessa marcha, compareceram cerca de 5 mil trabalhadores sindicalizados (Bento, 2000), revelando o estreitamento dos laços entre os ativistas negros e os sindicatos, o que não se via no caso dos protestos anteriores. Se o leitor se lembrar, durante os eventos do centenário, realçamos que os ativistas reclamaram da ausência do apoio de outras organi-

\footnotetext{
${ }^{20}$ Ver documentário da Macha Zumbi dos Palmares, consultado em acervo particular.

${ }^{21}$ Essa hipótese se torna mais plausível quando observamos as representações públicas de Vicentinho enquanto legislador. No campo em que realizei esta pesquisa, assisti a dois discursos de Vicentinho, um na marcha noturna e outro no $30^{\circ}$ aniversário do MNU. Em ambos, declarava-se negro e comprometido com as reivindicações do movimento.
} 
zações de classe. Então, essa presença expressiva de trabalhadores ligados aos sindicatos sela alianças com o movimento negro que vinham sendo costuradas por seus militantes nos últimos anos. Um sindicalista da CUT-MG, que participou desse protesto, esteve atento às implicações dessas alianças: “a partir da Marcha Zumbi pela Vida não dá mais para o movimento sindical fechar os olhos na questão da luta contra o racismo na sociedade brasileira. E neste sentido a tendência é de ampliar cada vez mais esta aliança"22.

As alianças mais intensas entre os negros e o sindicalismo têm sido feitas há duas décadas por meio da inserção de algumas lideranças negras nos sindicatos. Em São Paulo, essa aproximação formal ocorreu com o Conselho Estadual da Comunidade Negra, que promovia articulações e encontros de sindicalistas negros, chegando a designar uma equipe de trabalho só para organizar eventos e debates, através de um setor voltado para as relações de trabalho ${ }^{23}$. Depois do Conselho Estadual, nos anos 1990, organizações negras como o Centro de Estudos e Relações de Trabalho e Desigualdades, o CEERT, atuaram fortemente na formação de quadros sindicalistas, cujo resultado se fez notar no "surgimento de órgãos [no interior do sindicato] como o objetivo de abordar especificamente a problemática das relações raciais" (Bento, 2000, p. 321), o que ocorreu inicialmente na Central Única dos Trabalhadores, mas logo também alcançou outras entidades sindicais $^{24}$. As ações conjuntas com as centrais trabalhistas expressam bem os ganhos do movimento negro no interior

\footnotetext{
${ }^{22}$ Depoimento extraído do vídeo de registro da Marcha Zumbi dos Palmares, consultado em acervo particular.

23 "Em 1986, paradoxalmente a partir de uma iniciativa do Conselho da Comunidade Estadual de Participação e Desenvolvimento da Comunidade Negra do Estado de São Paulo, um órgão governamental, foi realizado em São Paulo, o '1”. Encontro Estadual de Sindicalistas Negros', que significa um acontecimento importante entre negros sindicalistas" (Bento, 2000, p.327).

${ }^{24}$ Por exemplo, em 1990 a Confederação Geral dos Trabalhadores fez no Rio de Janeiro um encontro no qual aprovou a criação de uma Comissão Nacional da CGT contra a discriminação racial (Bento, 2000, p. 328).
} 
do sindicalismo brasileiro, o que pode ser notado nas Conferências Internacionais pela Igualdade Racial, ocorridas no Brasil e nos EUA na primeira metade da década de 1990, e na construção do Instituto Interamericano para a Igualdade Racial, a Inspir, organizada pela CGT, CUT e Força Sindical, em 1995, no qual Vicentinho assumiu a direção como presidente fundador (Vicentinho, 2008).

Com esse histórico de articulações, não é de se estranhar o empenho desse líder sindical, bem como a presença numerosa de outros sindicalistas na Marcha do Tricentenário. Nascimento e Larkin (2000) consideram que essa relação de proximidade entre os dois movimentos é resultante da inserção dos militantes negros nos sindicatos, o que teria sido mediado pelos partidos políticos. Segundo eles, uma vez nas estruturas partidárias, os ativistas teriam acessado os principais sindicatos do país, influenciando-os politicamente. Desse modo, oferecem uma explicação complementar 60 àquela apresentada por Bento, cujo enfoque foi tanto para estruturas estatais como para organizações não governamentais. $\mathrm{O}$ argumento de Nascimento e Larkin parece ainda mais convincente quando atentamos para o depoimento de um ativista negro, inserido em partido político. Segundo ele, na época da Marcha dos 300 anos de Zumbi, "do ponto de vista partidário, a gente tinha, em 1995, organizações em quase todos os partidos, seja de direita seja de esquerda: PT, PC do B, PCB, PCB, PDT, PSB, o próprio PMDB, todos eles já tinham agrupamentos negros"25.

Além de maior abertura na sociedade civil, que gerou a possibilidade de assumir compromissos com demais movimentos, a Marcha dos 300 anos da Morte de Zumbi contava com uma abertura maior das estruturas estatais. Assim, esse evento logrou obter uma sessão solene no Congresso Nacio-

\footnotetext{
${ }^{25}$ Depoimento de Flávio Jorge Rodrigues da Silva concedido a Alberti e Pereira (2007, p. 349).
} 
nal, onde o movimento tinha o apoio de alguns parlamentares, como Paulo Paim, deputado federal pelo PT-RS, que defendia as populações quilombolas, e fazia eco às campanhas políticas negras gaúchas ${ }^{26}$.

Diferentemente de antes, a marcha representava um ritual que culminaria com o encontro entre o presidente da República e a comitiva nacional do movimento ${ }^{27}$. Nesse encontro, alguns de seus ministros, como Paulo Renato e Edson Arantes do Nascimento, o Pelé, se fizeram presentes, quando os ativistas entregaram um documento formal no qual apresentavam suas reivindicações, "denunciando o racismo, defendendo a inclusão dos negros na sociedade brasileira e apresentando propostas concretas de políticas públicas" (Marcha Zumbi, 1995a). Nos dizeres de Edson Cardoso, esse evento marcava um novo tipo de intervenção do movimento negro junto ao Estado:

Chegamos aqui após percorrermos um longo caminho e acreditamos que a partir desse momento a questão racial deixar de ficar no confinamento do cultural, onde o Estado intervém no carnaval liberando verbas para o desfile de bloco. O que a marcha veio exigir da representação política do Estado brasileiro é que o orçamento da união defina recursos explicitamente para superar as desigualdades raciais no campo da educação, no campo da saúde, da comunicação e do emprego ${ }^{28}$.

\footnotetext{
${ }^{26}$ Entrevista de Paim concedida para o documentário Marcha de Zumbi de Palmares, consultado em acervo particular.

27 As organizações que fizeram parte da direção nacional do evento são: Agentes de Pastoral Negros (APNs), Central de Movimentos Populares, Confederação Geral dos trabalhadores (CGT), Comunidades Negras Rurais, Central Única dos Trabalhadores (CUT), Força Sindical, Fórum Nacional de Entidades Negras, Fórum de Mulheres Negras, Movimento Negro Unificado (MNU), Movimento Pelas Reparações (MPR), União de Negros pela Igualdade (Unegro) e Grupo de União e Consciência Negra (Grucon), dentre outras.

${ }_{28}$ Depoimento extraído do documentário Marcha de Zumbi dos Palmares, consultado em acervo particular.
} 
$\mathrm{Na}$ avaliação do ativista, surgiria um elemento novo para a política do movimento negro dos anos 1990 em relação à década anterior. No plano estatal, uma conquista dos protestos do centenário foi a construção da Fundação Palmares, um órgão ligado ao Ministério da Cultura, o qual canalizava certas demandas do movimento ligadas ao campo cultural, mas sem capacidade institucional para intervir na redução das desigualdades. Ademais, as administrações estaduais costumam promover grupos negros apenas durante o carnaval, o que fica nítido na pesquisa de Souza (2006) sobre o Ilê Aiyê no estado da Bahia. Diferentemente desse tipo de relação - que se estendia para o Brasil inteiro -, a proposta da Marcha de 1995 tinha um caráter mais ousado: o enfrentamento das desigualdades raciais, exigindo para isso verbas específicas do Estado para lidar com esses problemas.

A contraproposta do governo Fernando Henrique não foi outra senão instituir um grupo de trabalho para debater 62 a questão de forma "criativa" 29 . Assim, o resultado do protesto foi o decreto presidencial que formava um Grupo de Trabalho Interministerial (GTI) com objetivo de promover políticas para "a valorização da população negra".

A função do grupo seria estudar propostas para o desenvolvimento e participação da população negra, considerando que para isso seria necessário "propor ações integradas de combate à discriminação racial"30. Um ativista do movimento negro carioca que esteve envolvido na Marcha do Centenário da Abolição, e, naquela década, já tinha fundado sua própria organização não governamental, o Centro

\footnotetext{
${ }^{29}$ No seu discurso de abertura do Seminário Multiculturalismo e Racismo organizado em função do Grupo de Trabalho Interministerial, FHC incitou os pesquisadores convidados a serem criativos perante o desafio de construir políticas públicas para população negra. Em suas palavras: "Desafio os senhores: criem. Seguramente, em um grupo tão vasto como este, além da inteligência bem-repartida, deve haver alguns com muita criatividade. O governo está tentando explorar a criatividade dos senhores, porque a nossa está esgotada" (Cardoso, 1996, p. 17).

${ }^{30}$ Decreto do Presidente da República em 20 de novembro de 1995.
} 
de Articulações de Populações Marginalizadas (Ceap), analisando os desdobramentos do protesto de 1995, avaliou as conquistas do movimento negro do seguinte modo:

Pela primeira vez na história do Brasil o Estado brasileiro tem que reconhecer que ele é racista e que a sociedade é racista e isso levou inclusive o governo brasileiro a instituir uma comissão interministerial para tratar políticas públicas para a população negra e isso foi um fato muito importante e foi uma conquista da marcha ${ }^{31}$.

No discurso negro, lideranças teriam pressionado o presidente, que respondeu imediatamente com a construção do GTI. Isso realmente aconteceu em alguma medida, mas exigiu também articulações no interior do governo. Um ativista negro com longa trajetória no aparelho público estatal apresenta uma versão diferente, diminuindo o protagonismo da Marcha. Ivair Alves dos Santos, que geriu o Conselho da Comunidade Negra do estado de São Paulo nos anos da redemocratização e atuava naquele momento na gestão de Fernando Henrique Cardoso, numa secretaria do Ministério da Justiça, realça uma articulação no interior do Estado, feita por ativistas e funcionários negros ligados ao governo:

O GTI, como disse, foi praticamente uma reprodução em larga escala do que a gente fez: era abrir espaço etc. e tal. Mas, na verdade, o que nos norteava era criar bases para que as pessoas entendessem que o racismo era uma coisa de política pública e criar algum substrato para discutir ação afirmativa. Quando a marcha Zumbi dos Palmares chegou aqui, deu a impressão de que a Marcha criou o GTI. Mas ${ }^{31}$ Depoimento de Ivanir dos Santos ao documentário Marcha Zumbi dos Palma-
res, em 1995. 
na verdade o GTI já estava pronto. Foi uma coisa que foi construída no governo. Não foi feita pela sociedade civil. O governo fez e apresentou ${ }^{32}$.

Mais do que uma simples confronto de pontos de vista, o comentário indica processos de diferenciação no interior do ativismo, apontando cada vez mais para sua institucionalização. São exatamente esses atores políticos que tencionaram no interior da burocracia estatal pela inserção de demandas políticas oriundas do movimento social.

Sob esse prisma, se faz entender a constituição do GTI, ligado ao Ministério da Justiça, que passou a vigorar em 1996. Ele possuía representantes de vários ministérios e ativistas do movimento negro, tendo como presidente Hélio Santos, que dirigira na década anterior o primeiro Conselho da Comunidade Negra da cidade de São Paulo. No evento de abertura do grupo de trabalho, FHC chamou um 64 grupo de intelectuais brasileiros e estrangeiros para debater a temática e apontar algumas possibilidades de ação política. No discurso que inaugurava as atividades, lembrou aos presentes o seu trabalho sobre relações raciais, nos anos 1950, como assistente de Florestan Fernandes. Investido de autoridade de intelectual, o presidente também assinalou que "o Brasil é uma nação multirracial e disso se orgulha, porque considera que essa diversidade cultural e étnica é fundamental para o mundo contemporâneo" (Cardoso, 1996, p.13). Mais do que uma sociedade multirracial, o presidente assinalou que o país possuía profundas desigualdades de todos os tipos, inclusive de raça, de cor e de cultura. Diante dessa nossa formação nacional, que guardava certa ambiguidade que nos é cara, Fernando Henrique considerava importante buscar soluções para tais problemas de forma criativa e original. Um fato parecia consensual: era

${ }^{32}$ Depoimento de Ivair Alves dos Santos concedido a Alberti e Pereira (2007, p. 355). 
preciso mudanças para reverter o quadro de discriminação por cor. Nas palavras dele:

Há uma repetição de discriminação e há a inaceitabilidade do preconceito. Isso tem que ser desmascarado, tem de ser, realmente, contra-atacado, não só verbalmente, mas também em termos de mecanismos e processos que possam levar a uma transformação, no sentido de uma relação mais democrática, entre raças, entre grupos sociais e entre as classes (1996, p. 16).

Apesar do discurso presidencial progressista em relação aos problemas raciais no Brasil ${ }^{33}$, os desdobramentos das atividades do GTI não deram resultados compatíveis ao sofisticado nível de discussão, o qual, aliás, pretendeu assumir os problemas de desigualdade e discriminação raciais sem se desfazer da democracia racial como um ideal da nação brasileira. Segundo Sérgio Costa (2006), as discriminações indiretas contra negros, como, por exemplo, aquelas relativas ao sistema educacional não receberam medidas combativas. Já Telles considerou que "como resultado o governo Cardoso hesitou na concretização dos objetivos que havia colocado inicialmente" (2003, p. 175). Pelo visto, na opinião dos analistas, o GTI parecia ser bastante promissor em relação a medidas concretas para coibir discriminação racial, porém frustrou as expectativas de muitos quanto à concretude das ações políticas.

Em que pese os limites do GTI para desenvolver efetivamente políticas públicas, o que nos interessa salientar é que um novo espaço se abria no interior da esfera estatal para a discussão da pauta levantada pelo movimento negro. A rela-

\footnotetext{
${ }^{33}$ Muitos analistas defendem que o discurso de FHC é bastante avançado, pois ele estaria reconhecendo a existência de racismo no Brasil e isso era um fato inédito na história presidencial brasileira (Telles, 2003; Nascimento e Larckin, 2001).
} 
ção entre Estado e movimento sofreu mudanças ${ }^{34}$. Em certa medida, os pronunciamentos das autoridades nacionais já passavam a ser estrategicamente mobilizados pelos ativistas a fim de se constituir um consenso no âmbito do poder público acerca da existência de um problema racial no país e da necessidade de criar condições efetivas para resolvê-lo.

Essas mudanças reverberaram sobre o próprio movimento, que interpretou aquele protesto como uma ação vitoriosa para a mobilização negra de todo o país. Sueli Carneiro, representante executiva da ONG Geledés, avalia que "depois do centenário da Abolição, das ações, das marchas que fizemos por conta do centenário, a marcha Zumbi dos Palmares pela cidadania e a vida, de 1995, foi o fato político mais importante do movimento negro contemporâneo"35. Certamente, esse evento fortaleceu ainda mais o movimento, que passou a usar o repertório da Marcha do Tricentenário em escala estadual e municipal para instituir o feriado 66 do 20 de Novembro em diferentes partes do país. Mais do que um evento episódico ou reivindicativo, com o passar dos anos, a marcha tornou-se também um evento do calendário da mobilização negra brasileira e tem sido realizada anualmente em diversas capitais do Brasil, mesmo naquelas em que o feriado já é uma conquista.

\footnotetext{
${ }^{34}$ Do ponto de vista dos resultados concretos, o único avanço mais contundente apontado pela literatura ocorreu no campo da saúde. Segundo Monteiro e Maio, "a proposta de uma política com recorte racial na área da saúde pública no Brasil só ganhou visibilidade no Governo Fernando Henrique Cardoso". E acrescentam que essa visibilidade veio no contexto do formação do GTI: "foi nesse ambiente de discussão que ocorreu ainda no primeiro semestre de 1996 a mesa redonda sobre a saúde da população negra", o qual contava com cientistas, ativistas do movimento negros e outros técnicos das áreas de saúde. A inclusão do quesito cor/raça nos formulários oficiais de nascimento e óbito foi uma das aquisições no ano de 1996. Afora essa conquista, os autores elencam o programa de combate à anemia falciforme como uma das reivindicações atendidas ainda na vigência do governo FHC (2008, p. 127).

${ }^{35}$ Depoimento de Sueli Carneiro a Alberti e Pereira (2007, p. 345).
} 


\section{Encenando a história: Marcha Noturna pela Democracia Racial}

A marcha noturna pela democracia racial é o exemplo mais bem-acabado de um novo perfil de protesto negro no Brasil. Ela ocorre na capital paulista há quinze anos, sem interrupções, desde 1996, quando um grupo de cerca de oitenta pessoas, às vésperas do 13 de Maio, realizou uma caminhada de aproximadamente duas horas pelo centro velho de São Paulo, partindo da Igreja da Nossa Senhora da Boa Morte até a Igreja do Rosário dos Homens Pretos. Em seu histórico, a marcha contou com a participação de organizações negras do município e região metropolitana, sendo a entidade Instituto do Negro Padre Batista a principal responsável pela sua organização desde 1997. Naquele ano, o protesto se incorporou ao calendário turístico da cidade, por iniciativa dos seus ativistas, tendo-se difundido por outras cidades paulistas ${ }^{36}$.

Sua fundadora, a advogada Maria da Penha Guimarães, conta que a ideia desse evento nada mais foi do que um sonho, numa época em que "dormia e acordava pensando em negro". A trajetória e o sonho dessa ativista nos faz compreender a estrutura e o simbolismo da marcha noturna do 13 de maio e a sua novidade: a exaltação do protesto litúrgico e expressivo. Para tanto, traçaremos em alto relevo a trajetória individual e a posição da ativista no entrelaçamento das áreas laborais, políticas e religiosas de sua vida, iluminando os aspectos relevantes de sua experiência para o processo criativo do protesto em tela.

À época de seu sonho, Maria da Penha era integrante da Ordem dos Advogados do Brasil (OAB) e possuía um escritório no Largo do Paissandu, em frente à Igreja do

\footnotetext{
${ }^{36}$ Esse é o caso de Suzano, que tem realizado a Marcha Noturna, contando com o suporte do deputado estadual do PT José Candido. Na Baixada Santista, registrou também uma marcha noturna, que na sua quarta versão recebeu o nome "Abolição não concluída: 120 anos sem reparações" (Educafro, 2008).
} 
Rosário. Formada na prestigiosa Escola de Direito do Recife e tendo militado no Partido Comunista (PC) durante a sua juventude, a pernambucana chega à São Paulo no final da década de 1970 e passa a desenvolver atividades ligadas à sua área de formação até estabelecer o seu próprio escritório de advocacia. Na capital paulista, trabalhou para alguns sindicatos na região do $\mathrm{ABC}$ que, naquele tempo, lideravam as greves gerais do agitado cenário político brasileiro.

Maria da Penha também tinha uma trajetória marcada pela militância política em defesa da causa racial na organização civil Instituto Negro Padre Batista, criada em 1987, e especializada na defesa dos direitos humanos. Anos mais tarde, a advogada viria a ficar mais conhecida pelo famoso caso de direito internacional "Diniz versus Estado brasileiro", muito discutido entre os anos de 2006 e $2007^{37}$. Embora tenha se notabilizado por sua empreitada no âmbito dos 68 direitos humanos, sua importância para nós está na gênese do protesto noturno e na densa rede social e institucional em que estava inserida.

Segundo sua narrativa, a ativista sonhara com uma floresta fechada onde muitos "negros rebelados fugiam por uma mata e iluminavam seus caminhos com tochas, vestidos de preto". No folheto da organização da marcha, encontramos a afirmação de que sua origem estaria atrelada a um "sonho de resistência" e a "um pedido dos orixás”. Nele a xangozeira e filha de Nanã ${ }^{38}$ aparece como

\footnotetext{
37 Trata-se do caso de discriminação da empregada doméstica Simone André Diniz, levado à Organização dos Estados Americanos (OEA). Para mais detalhes dessa batalha judicial que se revelou Diniz contra o estado do Brasil, tendo o último perdido em tribunal internacional em favor da primeira, auxiliada tanto por entidades negras como pela OAB, ver Arantes (2007).

${ }^{38}$ Nanã é um orixá do panteão religioso do Candomblé. A intenção da informante ao afirmar a relação entre o sonho e sua pertença religiosa era sugerir que recebera uma revelação e, por isso, estava encarregada de cumprir alguns compromissos no mundo.
} 
a idealizadora da marcha. A advogada trabalhista afirma que seu "sonho" resolvia um desejo interior de apresentar uma alternativa interessante frente às costumeiras (e às vezes enfadonhas) "palestras" e "seminários" sobre o 13 de Maio, que já eram tradicionais na experiência de ativismo de sua geração.

$\mathrm{Na} \mathrm{OAB}$, ela tinha aliados naturais no grupo de trabalho que integrava a subcomissão da área de direitos humanos. Por isso, quando contou o sonho aos colegas, ela chegou rapidamente à ideia de uma marcha, ainda que com certo receio de que a proposta de uma caminhada no 13 de Maio também fosse ouvida. Segundo a ativista, as pessoas consideraram importante interpretar esse sonho à luz da luta antirracista que acontecia naquele momento. Como disse ter sonhado com escravos, homens vestidos de preto na floresta, considerou que a representação mais condizente com essa realidade deveria ser uma mensagem sobre a Abolição. Nessa trama de amizade e ativismo se iniciou a tessitura do protesto cujo objetivo último era a "igualdade dos negros na sociedade brasileira”.

Fruto desse entendimento coletivo, saiu às ruas a Primeira Marcha Noturna pela Democracia Racial, que trazia os dizeres: "Negro nas ruas na madrugada do 13 de Maio". Isso porque, segundo o panfleto, o movimento resolveu "trocar o dia pela madrugada: substituir os discursos pelo silêncio, trajar preto, usar a luz das velas no lugar da confortável luz solar e portar uma tarja branca"39. Na chamada do folheto, está presente aquele que deveria ser, na opinião dos militantes, um dos maiores desafios da democracia brasileira: o enfretamento efetivo da desigualdade racial.

Contudo, longe de apenas denunciar o racismo, a forma de protesto assumida pelo movimento na marcha

\footnotetext{
${ }^{39}$ Extraído do documento da Primeira Marcha Noturna. Consulta realizada no Instituto do Negro Padre Batista.
} 
noturna indicava que eles estavam conscientes de uma nova figuração da relação entre movimento negro e Estado. Diziam em seu panfleto: “os símbolos e a maneira de protestar representam as profundas mudanças que estão em curso na sociedade brasileira", resultantes dos esforços da militância negra, que enfatiza a dimensão simbólica e institucional, dentre elas a criminalização do racismo. Do ponto de vista simbólico, segundo o movimento "o mito da democracia racial" teria sofrido "golpes mortais", e a celebração dos 300 anos da morte de Zumbi, celebrados em marcha em Brasília, no ano anterior, seria exemplo disso.

Mas de onde vinha esse sonho que, sem grandes esforços, nos lembra discursos coletivamente estruturados pelo movimento negro ao longo de sua trajetória?

A ideia da marcha noturna, quando narrada pelos ativistas, remete ao protesto nacional de 1995, servindo-lhes 70 de inspiração imediata, porque ocorreu apenas um ano antes da inauguração da caminhada noturna. Mas também teve inspiração nas marchas pacifistas pelos Direitos Civis realizadas nos EUA, durante os anos 1960. A novidade para os ativistas contemporâneos está no turno em que o evento ocorria. Sair à noite era uma inovação no repertório do movimento negro, ao mesmo tempo em que se apresentava como alternativa simbólica ao "tabu" do 13 de Maio. A data, em suspenso, pelas restrições radicais do movimento negro, não poderia escapar à memória, mas também não poderia permanecer no imaginário nacional como dia folclórico. Desse impasse, a solução original apresentada conseguia manter o consenso estabelecido no interior do ativismo, ao mesmo tempo em que resguardava a tradição cívica de rememorar a liberdade dos negros.

Novidade também não havia na luta ideológica em torno do mito da democracia racial, marcado no slogan desse protesto. Sabemos que a disputa por imprimir um 
outro significado à expressão "democracia racial” vem sendo realizada desde meados do século XX pelo movimento negro. Guimarães e Macedo (2008) argumentam que esse ideário democrático, numa versão da militância política dos anos 1940, revela certos conteúdos do mito nacional, mas os mesmos quase sempre apresentam críticas contundentes ao preconceito de cor no Brasil. Ao contrário do que rezava o discurso nacional, a democracia racial negra daquele período constituía-se pelo discurso da segunda abolição - divulgada pela Frente Negra Brasileira - e pelas ideias de negritude, de inspiração dos intelectuais negros francófonos.

Desde então, o discurso pela democracia racial sofreu algumas modificações, Mués $(1991,1998)$ identifica nele fissuras significativas. Em seu entender, o movimento de 1970 rompe com a ideia de democracia racial tal como divulgada pelo Estado e passa a defender uma democracia plena, que significa agora a luta pela igualdade efetiva para negros. Tratava-se de um movimento duplo: a reinvenção da ideia de nação e a defesa de um estado realmente fundamentado num liberalismo igualitário.

\section{0 trajeto da marcha e seus simbolismos: os caminhos e os espaços da história ${ }^{40}$}

Às vésperas do 13 de Maio, um pequeno grupo de ativistas percorrem o centro velho de São Paulo em direção ao largo do Paissandu. Os militantes e representantes de organiza-

\footnotetext{
${ }^{40}$ A fundamentação histórica dos espaços percorridos pela marcha é atribuída pelo movimento aos esforços de pesquisa do Padre José Enes de Jesus, atual presidente do Instituto do Negro Padre Batista. Segundo seus ativistas, o padre teria feito uma dissertação de mestrado acerca desses pontos históricos levantados pelos ativistas; contudo, não tivemos acesso a tal dissertação. Toda a referência dos lugares em destaque pela marcha foi retirada de documentação pública da própria marcha, das entrevistas com seus fundadores e líderes, bem como da etnografia das marchas XI e XII. Ademais, a verificação da validade histórica das informações obtidas nessa documentação foi realizada a partir de consulta de trabalhos historiográficos correlatos aos temas postos em relevo pela marcha.
} 
ções negras caminham pelas ruas em duas filas paralelas, que representariam a forma pela qual os escravizados andavam em suas estratégias de fuga. Os toques de tambores ritmados ecoam pelas ruas centrais e acompanham os cânticos de candomblés entoados pelo povo de santo. As pessoas carregam tochas acesas, que são artefatos elaborados para realização desse protesto, espécie de lamparinas artesanais que alumiam a noite escura e ajudam a discernir os caminhos percorridos na caminhada. Além das tochas, são recomendados o uso de roupas pretas. Em fila indiana, com tochas acesas nas mãos e vestuário escuro - que fica mais colorido a cada ano -, os ativistas seguem carregando cartazes das suas respectivas associações.

A ideia da "falsa abolição" ou "abolição inacabada" é o slogan das últimas marchas; a passeata também conta com grandes fotografias de heróis e pessoas ilustres impressas em banners. Assim, as figuras de abolicionistas - como 72 André Rebouças, José do Patrocínio, Luis Gama - e de líderes de revoltas do Brasil escravagista - como Zumbi e Luiza Mahim - são particularmente reverenciadas. Esses últimos figuram no repertório do movimento como a imagem da resistência negra e da liberdade. Em oposição, a narrativa procura negar ou diminuir a ação de personagens consagrados pela história oficial, como a princesa Isabel e Joaquim Nabuco. Esses últimos só aparecem nos discursos nos momentos em que as lideranças querem denunciá-los por terem sido privilegiados pela história oficial, ofuscando o protagonismo negro na conquista de sua liberdade. As imagens desses heróis são colocadas lado a lado com líderes do movimento negro do século XX, como Adbias do Nascimento (1914-2011), Lélia Gonzalez (1935-1994) e Hamilton Cardoso (1954-1999), dentre outros. Esses intelectuais e quadros importantes do movimento negro percorrem as ruas de São Paulo junto a ativistas anônimos, levados pelas entidades de base. 
A marcha noturna segue um percurso muito particular no centro de São Paulo. A Igreja da Nossa Senhora da Boa Morte, localizada na rua do Carmo, na Sé, é o ponto de partida e o lugar de concentração dos ativistas, que ali aguardam a saída da caminhada. Na XII Marcha, os militantes concentraram-se nesse local embalados pelo Hino da Negritude ${ }^{41}$, sons de rap, grupos de samba e cantos de candomblé e umbanda, interrompidos, de tempos em tempos, por discursos de parlamentares, personalidades históricas e demais ativistas das organizações realizadoras do evento. Mas nem sempre foi assim. A adoção de atividades culturais para incentivar a permanência na espera da saída da marcha foi adotada como uma estratégia para garantir um número maior de pessoas. Trata-se de uma inovação que apareceu aos poucos com a função de constituir uma dimensão lúdica para os integrantes da marcha, atraindo também a atenção dos transeuntes vindos do trabalho.

A escolha da Igreja da Boa Morte explica-se por ser “onde escravos 'rebeldes' e condenados recebiam as últimas 'bênçãos' antes de serem executados" 42 durante o regime escravista. Para os organizadores da III Marcha Noturna: "esta igreja guarda o lamento de escravos condenados, que antes da sua execução passavam por ela a fim de expressar à Nossa Senhora um último desejo - 'uma boa morte", 43 .

${ }^{41}$ O Hino da Negritude foi composto por Eduardo Oliveira e registrado na Escola Nacional de Música da Universidade do Brasil, em 1966. O próprio compositor, na marcha, rege o canto solene diante da plateia que o acompanha. Algumas passagens da canção merecem destaque, porque convergem com os ideais da marcha noturna: "Que saibamos guardar estes símbolos/De um passado de heróico labor/Todos numa só voz/Bradam nossos avós:/Viver é lutar com destemor/ Para frente marchamos impávidos/Que a vitória nos há de sorrir/ Eia, pois, cidadãos/ Somos todos irmãos/Conquistando o melhor porvir". E no estrebilho, encontra-se: "ergue a tocha no alto da glória/Quem herói, nos combates, se fez/Pois, que as páginas da história,/São galardões aos negros de altivez”.

42 Documento da X Marcha Noturna, consultado no Instituto do Negro Padre Batista.

${ }^{43}$ Documento da III Marcha Noturna, consultado no Instituto do Negro Padre Batista. 
Os arredores da igreja também são repletos de significados para seus ativistas, por exemplo, na esquina da rua do Carmo com a rua Tabantiguera, que "guarda a memória da primeira forca de São Paulo" ", e a Praça da Sé, que possuía um pelourinho rememorado nos discursos realizados durante a caminhada. Se o passado escravista era relembrado naquele local, havia outro significado também importante para os militantes: a Igreja da Boa Morte tornou-se desde os anos 1980 a sede nacional dos Agentes da Pastoral dos Negros (APN), os quais são ativos na construção da marcha. Assim, memórias do passado longínquo e recente combinam-se na construção da história contada pelo movimento negro.

Saída da rua do Carmo, a caminhada segue em direção à praça da Sé, passando em frente à rua Venceslau Brás, onde se localiza a organização Padre Batista, local de ativismo contemporâneo. O largo da Sé faz lembrar também as crianças abandonadas, que, segundo a narrativa, eram 74 acolhidas e batizadas pelo bispo local. Tal interpretação é particularmente cara ao segmento católico do protesto.

Depois, seguem em direção ao largo do São Francisco, descem a rua São Bento, chegando à praça Antônio Prado, esquina com a 15 de Novembro, onde foi construída a antiga Igreja do Rosário dos Homens Pretos. Perto dela, encontra-se um cemitério invisível, onde os negros teriam sido enterrados durante o século XIX, visto apenas por aqueles que ouvem as narrativas emocionadas ao longo da caminhada. Mais adiante, avistam-se as escadarias do Teatro Municipal, o penúltimo ponto de parada da marcha. Lá, rememora-se a atitude do Movimento Negro Unificado, que ainda durante a ditadura denunciou as discriminações raciais, rompendo com o discurso da democracia racial e inaugurando uma nova forma de ativismo político, como já vimos em páginas anteriores.

${ }^{44}$ Documento da III Marcha Noturna, consultado no Instituto do Negro Padre Batista. 
O ponto final da caminhada é o largo do Paissandu, onde atualmente está localizada a Igreja Nossa Senhora do Rosário dos Homens Pretos, erigida em 1904. A atual igreja ainda guarda restos mortais que os ativistas acreditam ser de ex-escravos que atuaram no período da abolição. Ademais, trata-se de uma igreja que abrigava a irmandade negra mais poderosa do Brasil escravagista, a qual tinha liberação jurídica para compra de alforria de escravos. No desfecho de cada marcha, personalidades do ativismo leem o manifesto do protesto e depois todos abraçam à igreja, simbolizando o encontro com seus ancestrais, que teriam lutado pela liberdade. Assim, mal o 13 de Maio se inicia, fecham-se as cortinas da história, para que o dia chegue sem graça, como um outro qualquer, sem ares imperiais, sem a presunção do discurso oficial da República do Brasil. À noite, os negros roubam a cena e o significado do dia da Abolição, fortalecendo-o no repertório do movimento social, mesmo que para isso tenham que ajustar os ponteiros do relógio da história.

\section{Algumas considerações}

Ao término do artigo, talvez o leitor possa concluir que se encerrou o ciclo de protestos reivindicativos do movimento negro ou que as atuais passeatas e atos públicos não são mais do que encenações do jogo político, já que as "verdadeiras lutas" acontecem nas salas de negociação, em gabinetes governamentais. Esta não seria uma assertiva totalmente verdadeira. As evidências levantadas mostram que pensar as manifestações mediante a explicação das oportunidades políticas pode ajudar a entender esse ciclo de protestos do movimento negro, sem perder de vista que o maior acesso aos órgãos e governantes federais não implica necessariamente em abertura local (nos Estados, municípios ou instituições públicas e privadas). Os atos públicos da última década indicam a presença marcante de manifestações desse movimento social nas arenas municipais e estaduais. 
Esse histórico de protesto e de tentativas de mudança dos valores societários permitiu à população negra maior visualização nos canais de representação social, o que favoreceu a visibilidade pública e jurídica para os casos emblemáticos de agressão à dignidade humana de indivíduos pardos e pretos ${ }^{45}$.

Essa realidade só foi possível porque o movimento negro brasileiro passou por um processo de institucionalização jamais visto em sua história que, em certa medida, possibilitou a profissionalização e a especialização dos ativistas, bem como a formalização e a burocratização dos coletivos e das entidades. Muitas destas tornaram-se, aos poucos, associações civis formalmente mais complexas, cujo modelo exemplar é o de organização não governamental (Rios, 2009). Ademais, o Governo Federal na administração FHC, e, sobretudo, Lula, absorveu parte significativa dos quadros políticos negros, especialmente na construção da Seppir e 76 das leis e programas nacionais de promoção da igualdade racial (Lima, 2010), sem contar as comissões de controle público, que passaram a ser cada vez mais frequentados pelos ativistas. Tão importante quanto isso foi o ambiente político internacional, que ofereceu incentivos políticos e econômicos para a luta antirracista do país, seja na forma de conferências internacionais, promovidas pela Organização das Nações Unidas (Roland, 2000), seja pelo apoio financeiro de agências financiadoras internacionais, como a Fundação Ford (Telles, 2003).

Tal é o quadro contemporâneo do ativismo sobre o qual se abrem várias perspectivas analíticas. O crescimento

\footnotetext{
${ }^{45}$ Refiro-me diretamente a casos de assassinatos e agressões físicas e verbais em espaços públicos como "batidas policiais nas ruas" ou perseguições em espaços comerciais, como grandes supermercados, shoppings etc. Cada vez mais, intervenções localizadas de enfrentamento face a face despontam nos centros urbanos brasileiros como reações imediatas às formas de discriminação institucional. De modo geral, são formas pacíficas de constrangimento público que resultam em exigências de programas localizados de combate à discriminação.
} 
e êxito do movimento negro têm dependido cada vez mais de sua habilidade para aliar-se a setores da sociedade civil e do Estado, que há menos de três décadas conferiam pouca atenção às demandas do movimento organizado. O impacto dessa configuração de poder sobre a militância e suas investidas na esfera pública nacional alterou significativamente as relações entre raça e política na sociedade brasileira. $\mathrm{O}$ trânsito de militantes negros no Poder Executivo, Legislativo, o acesso constante ao Judiciário, a existência de órgãos públicos destinados exclusivamente às chamadas "políticas de igualdade racial”, o progressivo engajamento de deputados e senadores negros nas pautas do ativismo, sugerem alteração no significado dos protestos negros nacionais, que agora cede lugar para lutas contenciosas localizadas em contextos exemplares de discriminação. As marchas celebratórias, assim, só fazem sentido porque já podemos falar de uma tradição negra de protestos políticos ${ }^{46}$.

\section{Flavia Rios}

é doutoranda em sociologia pela FFLCH-USP e bolsista Fapesp.

\section{Referências bibliográficas}

ALBERTI, V.; PEREIRA, A. (orgs.) 2007. Histórias do movimento negro no Brasil: depoimentos ao CPDOC. Rio de Janeiro: Ed. FGV/ Pallas.

ARANTES, P. T. L. 2007. "O caso Simone Andrade Diniz e a luta contra o racismo estrutural no Brasil”. Direito, Estado e Sociedade, no 31, pp. 127-149. ANDREWS, G. R. 1991. "O protesto político negro em São Paulo: 18881989”. Estudos Afro-Asiáticos, no 21, pp. 27-48.

BAIRROS, L. 1996. "Orfeu e poder: uma perspectiva afro-americana sobre a política racial no Brasil”. Revista Afro-Ásia, no17, pp. 173-185.

BASTIDE, R; FERNANDES, F. 1955. Relações raciais entre negros e brancos em São Paulo. São Paulo: Anhembi.

\footnotetext{
${ }^{46}$ Para exemplificar esse perfil de protesto, registre-se o ato de comemoração dos 30 anos de MNU, realizado nas escadarias do Teatro Municipal de São Paulo, em julho de 2008.
} 
BENTO, M. A. S. 2000. "Racismo no trabalho: o movimento sindical e o Estado”. In: GUIMARÃES, A. S.; HUNTLEY, L. (orgs). 2000. Tirando a máscara. São Paulo: Paz e Terra.

CARDOSO, F. H. 1996. "Pronunciamento do Presidente da República na Abertura do Seminário Multiculturalismo e Racismo”. In: SOUZA, J. (org.). Multiculturalismo e Racismo: o papel da ação afirmativa nos Estados democráticos contemporâneos. Brasília: Ministério da Justiça.

CARDOSO, H. 1986. “O resgate de Zumbi”. Lua Nova, vol. 2, no 4, pp. 63-67.

CARDOSO, R. C. L. 1987. "Movimentos sociais na América Latina”. Revista Brasileira de Ciências Sociais, vol. 1, no 3, pp. 27-37.

CARVALHO, J. M. 2005. "O exército e os negros". In: Forças armadas e política no Brasil. Rio de Janeiro: Jorge Zahar.

CONTINS, M. 2005. Lideranças negras. Rio de Janeiro: Faperj/Aeroplano.

COSTA, S. 2006. Dois Atlânticos. Belo Horizonte: Ed. UFMG/Humanitas.

EDUCAFRO. 2008. "Marcha Noturna em Suzano". Disponível em <www. educafro.org.br>. Acesso em mai. 2008.

GARCIA, J. (org.). 2006. 25 anos 1980-2005: movimento negro no Brasil. Brasília: Fundação Palmares.

GONZALEZ, L. 1982. "O movimento negro na última década” In: GONZALEZ, L.; HASENBALG, C. A. (orgs.). O lugar do negro. Rio de Janeiro: Marco Zero.

GORENDER, J. 1990. "Sob o signo da negação". In: A escravidão reabilitada. São Paulo: Ática.

GUIMARÃES, A. S. A. 1999. Racismo e antirracismo no Brasil. São Paulo: Ed. 34. 2008. Preconceito racial: modos, temas e tempos. São Paulo: Cortez.

; MACEDO, M. 2008. "Diário trabalhista e democracia racial negra dos anos de 1940”. Dados, vol. 51, pp. 143-182.

HANCHARD, M. 2001 Orfeu e o poder: o movimento negro no Rio de Janeiro e São Paulo (1945-1988). Rio de Janeiro: Eduerj.

LIMA, M. 2010. "Desigualdades raciais e políticas públicas: ações afirmativas no governo Lula”. Novos Estudos, no 87, pp. 77-95.

HASENBALG, Carlos. 2005. Discriminação e desigualdades raciais no Brasil. Belo Horizonte: Ed. UFMG.

KÖSSLING, K. S. 2007 As lutas antirracistas de afro-descendentes sob vigilância do Deops/SP (1964-1983). Dissertação de mestrado. São Paulo: FFLCH-USP.

KOWARICK, L. 1987. "Movimentos sociais urbanos no Brasil contemporâneo: uma análise da literatura”. Revista Brasileira de Ciências Sociais, vol. 1, nํ 3, pp. 38-50. 
MARCHA DE ZUMBI DOS PALMARES. 1995a. Documento final de divulgação. Disponível em <http:/ /www.casadeculturadamulhernegra.org. br/1995>. Acesso em 15/08/2008.

1995b. Relatório final. Disponível em < http://www.casadeculturadamulhernegra.org.br/1995>. Acesso em 15/08/2008.

NASCIMENTO, L. E; NASCIMENTO, A. 2000. "Reflexões sobre o movimento negro no Brasil, 1938-1997”. In: GUIMARÃES, A. S.; HUNTLEY, L. (orgs.). 2000. Tirando a máscara. São Paulo: Paz e Terra.

RATTS, A; RIOS, F. 2010. Lélia Gonzalez. São Paulo: Selo Negro.

ROLAND, E. 2000. "Movimento de mulheres negras brasileiras". In: GUIMARÃES, A. S.; HUNTLEY, L. (orgs.). 2000. Tirando a máscara. São Paulo: Paz e Terra.

RUFINO, J. 1985. "O movimento negro e crise brasileira". Revista Politica e Administração, vol. 2, pp. 287-307.

SCHWARCZ, L. K. M. 1990. "De festa também se vive: reflexões sobre o centenário da abolição em São Paulo”. Estudos Afro-Asiáticos, n.18, pp. 13-25.

SAILLANT, F; ARAUJO, A. L. 2006. "Zumbi: mort, mémoire et résistance”. Frontières, vol. 19, no1, pp. 37-43.

SILVA, J. 1994. Centro de cultura e arte negra: trajetória e consciência étnica. Dissertação de mestrado. São Paulo: PUC.

SILVEIRA, O. 2003. "Vinte de novembro: história e conteúdo". In: SILVERIO, V. R.; SILVA, P. B. G. (orgs.): Entre a injustiça simbólica e a injustiça econômica. Inep: Brasília.

SOUZA, J. 1996. Multiculturalismo e racismo: o papel da ação afirmativa nos Estados democráticos contemporâneos. Brasília: Ministério da Justiça.

SOUZA JUNIOR, W. A. 2006. O Ilê Aiyê e a relação com o Estado. Dissertação de mestrado. Salvador: FFCH-UFBA.

TARROW, S. 2006. Power in movement: social movement and contentious politics. Cambridge: Cambridge University Press.

TELLES, E. 2003. Racismo à brasileira. Rio de Janeiro: Relume-Dumará.

TILLY, C. 2005. "Invention, diffusion and transformation of social movement repertoire”. In: Identities, boundaries and social ties. London: Paradigm.

VICENTINHO. 2008. "Histórico e Vida Pessoal de Vicente Paulo da Silva". Disponível em <http:/ / www.vicentinho.org.br>. Acesso em 15/10/2008. 


\section{O PROTESTO NEGRO NO BRASIL CONTEMPORÂNEO (1978-2010) FLAVIA RIOS}

Resumo: O protesto de rua é, no presente artigo, a unidade analítica privilegiada para o estudo da trajetória política do movimento negro brasileiro contemporâneo. A análise compreende o processo político que vai desde o seu ato inaugural - que abriria as cortinas de um novo ciclo de mobilização no bojo das lutas pela liberação democrática numa sociedade fortemente mobilizada contra a ditadura -, até a institucionalização de suas demandas e lideranças políticas, estas últimas agora agentes da igualdade racial junto ao poder público instituído.

Palavras-Chave: Movimento negro; Protesto, Democratização; Identidade coletiva.

316 THE BLACK PROTEST IN CONTEMIPORARY BRAZIL (1978-2010)

Abstract: The street protest is, in this article, the privileged analytical unit to study the political history of Brazilian black movement. The analysis includes the political process since its inaugural actwhich would open the curtains of a new cycle of mobilization in the nest of struggles in a democratic society strongly mobilized against dictatorship - to the institucionalization of its demands and its political leaders, who are now agents of the racial equality at the instituted public power.

Keywords: Black movement; Protest, Democratization; Collective identity.

Recebido: 04/08/2011 Aprovado: 17/10/2011 